\title{
An Economic Based Approach for Optimal and Secure Reactive Power Provision in Deregulated Environments
}

\author{
Amin Kargarian (Corresponding author) \\ Islamic Azad University, Safashahr Branch \\ PO box 73961-66561, Safashahr, Iran \\ Tel: 98-917-306-8366 E-mail: amin.kargarian@gmail.com \\ Fahime Ebrahimi \\ Islamic Azad University, Safashahr Branch \\ PO box 73961-66561, Safashahr, Iran \\ Tel: 98-917-729-1359_E-mail: f_ebrahimi596@yahoo.com \\ Mehdi Sarikhani \\ Islamic Azad University, Safashahr Branch \\ PO box 73961-66561, Safashahr, Iran \\ Tel: 98-917-352-6043Ｅ-mail: mehdi_sarikhani@yahoo.com
}

Received: January 27, 2011

Accepted: March 9, 2011

doi:10.5539/mas.v5n3p111

\begin{abstract}
In deregulated electricity markets, reactive power provision is one of the most important ancillary services which is vital for reliable and secure operation of the system. In all electricity markets, economic issues play an important role in market scheduling. This paper presents an algorithm to find optimal reactive power market schedule. The proposed algorithm seeks to minimize a novel three-component payment function which precisely considers economic issues in the market. Two first parts of this function are reactive power provision cost and transmission loss payment. Moreover, another important part of this payment function, which has not considered in the time of reactive power market clearing in literature, is transmission charge payment. As it is shown in simulation results, this term of the function can importantly impact on final reactive power market schedule and consequently on total market payment and final market schedule. Furthermore, due to significant impact of reactive power on system voltage stability, the algorithm tries to schedule reactive power market with an adequate voltage security margin. Sequential quadratic programming is employed to clear the algorithm which is a nonlinear constrained optimization problem. The proposed algorithm is applied on IEEE-24 bus test system with satisfactory results.
\end{abstract}

Keywords: Reactive power market clearing, Transmission loss, Transmission charge payment, Voltage security margin, Nonlinear constrained optimization

\section{Introduction}

Since the past few decades, many electric industries around the globe have restructured. Among different issues in deregulated environments, ancillary services are one of the most important subjects which have essential role in power system operation and security (Shahidehpour, Yamin, \& Li, 2002; Raoofat \& Kargarian; 2009). According to FERC Order No.888, there are six different ancillary services (FERC Staff Report, 2005). In almost all electricity markets, system operators are responsible for providing these services for the system.

Reactive power provision is one important ancillary service which has significant impact on power system stability and security (Kargarian, Raoofat, 2011). In a typical market, the system operator should provide adequate reactive power to ensure system security. For example, the lack of reactive power can cause voltage drop in some buses and consequently it may result in system voltage instability (P. Kundur. 1994).

Different electricity markets around the world use different methods for reactive power market clearing 
(Kargarian, Raoofat, \& Mohammadi, 2011). As an example, the New York ISO (NYISO) uses an embedded cost to pay generators for their reactive power services. If any generator needs to reduce its active power in order to increase its reactive power generation, the NYISO should pay a lost opportunity cost to the generator (New York Independent System Operator, 2008). In California market, the generators do not receive any payments for reactive power provision when they are working in the range of 0.9 lagging to 0.95 leading power factors. To procure a reactive power beyond these limits, the California ISO (CAISO) should pay off the generators for their reactive power including lost opportunity cost (California Independent System Operator Corporation, 2000).

In almost all electricity markets, the system operators try provide adequate reactive power with the minimum payment considering system constraints. Different optimization problems are proposed in literature which most of them define the total reactive power payment as an important object of the optimization (Bhattacharya, \& Zhong, 2001; Hao, 2003; Hasanpour, Ghazi, \& Javidi, 2009). But, considering only reactive power cost may cause increasing total system energy loss which usually results in increasing total market payment.

On the other hand, transmission network is a key section of a power system which transfers electrical power from generators to customers and distribution companies (Shahidehpour, Yamin, \& Li. 2002). In most electricity markets, transmission owners and operators are paid for transferring electrical power through the lines. Several approaches have been proposed for transmission charge payment most of which depend on transmission lines power flow (Shahidehpour, Yamin, \& Li; 2002). Therefore, reactive power schedule influences the transmission charge payment and consequently total market payment.

Moreover, reactive power influences on system voltage stability (Kargarian, \& Raoofat, 2011; Kundur, 1994). If the system operator only considers economic aspect of reactive power market, it will result in a market schedule with the minimum market payment. But, this operating point may move the system toward voltage instability points. Therefore, the system operator should take into account the impact of reactive power market on the system voltage security margin.

This paper presents a novel reactive power market clearing algorithm for forward ancillary services market. The proposed algorithm is an OPF formulation which accurately considers economic aspects of reactive power market. A novel three-component payment function is suggested to be minimized as the objective function of the optimization. This function precisely models the economic issues in the market. The first term of the function is reactive power cost. In addition, because of the impact of reactive power schedule on power flow in transmission lines, transmission loss cost and transmission charge payment are two other parts of the three-component objective function. Also, to guarantee the power system stability as a vital issue during market operation, the proposed algorithm seeks to find the best schedule with the adequate voltage security margin. The proposed market clearing algorithm is a nonlinear constrained optimization problem. To solve the problem, sequential quadratic programming is employed. The algorithm is applied on IEEE 24-bus test system with suitable results.

\section{Cost of reactive power provided by market participants}

According to NERC operation policy 10, only reactive power produced by synchronous generators has been considered as ancillary service and is eligible for financial compensation (North Amer. Elect. Reliability Council., 2001). Some references deem it is necessary to pay the other reactive power providers such as capacitor banks, synchronous condensers and FACTS devices (FERC Staff Report, 2005). In Australia both synchronous generators and synchronous condensers receive payments for reactive power provision (National Electricity Market Management Company, 2001).

In this paper, reactive power provided by synchronous generators, condensers and capacitor banks are assumed as ancillary service which should be compensated by the system operator.

\subsection{Cost of generator's reactive power}

Different reactive power payment structures can be used for synchronous generators (Bhattacharya, \& Zhong, 2001; Hao, 2003; Hasanpour, Ghazi \& Javidi, 2009). In (Hasanpour, Ghazi \& Javidi, 2009) a quadratic reactive power cost curve has been proposed for a typical synchronous generator. This cost curve models the investment cost, operational cost and also lost opportunity cost of a synchronous generator accurately. It has been defined as follows:

$$
\operatorname{Cos}\left(Q_{g i}\right)=a_{q, i} Q_{g i}{ }^{2}+b_{q, i} Q_{g i}+c_{q, i}
$$

Where Qgi is reactive power output of ith generator; and aq, bq and cq are constant coefficients. As it is described in (Hasanpour, Ghazi \& Javidi, 2009), knowing active power cost curve of a generator, its capability 
curve and maximum amount of active and reactive power of that generator, these constant coefficients can be estimated accurately using a suitable interpolation technique. This equation can provide accurate results in reactive power market while it is very simple for implementation.

\subsection{Cost of condenser's reactive power}

Synchronous condenser is a synchronous machine without any prime mover which can provide only reactive power. The reactive power cost curve of a condenser consists of the investment cost and operating cost. The operating cost of a synchronous condenser includes running cost and investment cost. The running cost contains the cost of energy consumed to overcome the mechanical friction and electrical loss, and the maintenance cost. Consequently, the reactive power cost curve of a synchronous condenser can be formulated by (2) (Dai et al., 2003):

$\operatorname{Cost}\left(Q_{c i}\right)=\left(\beta_{c i}+\sigma_{c i}\right) Q_{c i}$

Where Qci is the reactive power output of condenser, $\sigma$ (\$Mvar-h) is the operating cost of condenser and $\beta \mathrm{ci}$ (\$/Mvar-h) which is formulated by (3) models the investment cost.

$\beta_{c i}=\frac{\text { Capital investment } \cos t}{8760 \times \text { lifespan } \times \text { average usage ret }}$

\subsection{Cost of capacitor's reactive power}

The charge for using capacitors is similar to synchronous condensers and can be expressed by (2). The capacitors have little operating cost and their reactive power production costs have been considered to be calculated based on their capital investment costs (Dai et al., 2003). Hence, for the capacitors, in equation (2) the parameter $\sigma$ should be set to be zero.

\section{Transmission loss cost}

If the operator only seeks to minimize cost of reactive power provision, it will contract with providers which offer the minimum prices. But, it may result in increasing transmission energy loss and consequently increasing total system payment. Therefore, cost of both reactive power provision and transmission energy loss should be considered in the stage of reactive power market clearing (S. Hao. 2003). The cost of transmission loss can be defined as (4):

$$
\operatorname{Cost}\left(P_{\text {loss }}\right)=\lambda P_{\text {loss }}
$$

Where $\lambda$ is market energy price and $P_{\text {loss }}$ is the total transmission loss.

\section{Transmission charge payment}

In most restructured power systems, as a result of transferring electrical power through transmission lines, the system operator should pay charge to transmission owners. Many transmission charge payment mechanisms have been proposed in literature which most of them consist of two components related to active and reactive power flow (Shahidehpour, Yamin, \& Li, 2002).

MVAr-Mile is a usual method for transmission pricing which considers reactive power transmitted through the network lines (Shahidehpour, Yamin, \& Li, 2002). These approaches require AC power flow calculations. The system operator should pay charge to transmission owner according to length of the line (mile), the cost per MVAr per unit length of the line (\$MVAr-mile) and the magnitude of reactive power flow on the line. This manner can be formulated as below (Shahidehpour, Yamin, \& Li, 2002):

$$
R P T C=\sum_{i \in \text { line }} M V A r_{i} \times C_{q i} \times L M_{i}
$$

In (5), RPTC is Reactive Power Transmission Charge for all lines of the system. The parameters $\mathrm{MVAr}_{\mathrm{i}}, \mathrm{C}_{\mathrm{qi}}$ and $\mathrm{L}_{\mathrm{Mi}}$ are reactive power flow, cost per MVAr per unit length and length (mile) of $i^{\text {th }}$ line, respectively.

The transmission charge for active power flow in the network lines (MW-Mile) can be formulated similar to (5). But, it is better to consider this cost in active power scheduling. In this paper, RPTC is only considered in reactive power market settlement.

\section{Voltage stability assessment}

The voltage security is defined as an important subject in power systems and should be taken into account in many programming and planning problems (Kundur, 1994). To ensure reliable operation of the power system, it is necessary to maintain adequate voltage security margin in both normal condition and under contingency cases. Therefore, maximization of voltage security margin is considered in this paper as one objective of the multiobjective optimal reactive power planning.

There are several approaches to estimate voltage security margin in a typical power system. Using different 
voltage security indices is a useful and conventional method for voltage security margin assessment (Moghavvemi, \& Omar, 1998). Various indices for determination of the distance to the voltage collapse or instability has been proposed; active power margin based on $\mathrm{P}-\mathrm{V}$ curves, reactive power margin based on Q-V curves and $\mathrm{L}_{\mathrm{mn}}$ index are some good examples of these indices (Kundur, 1994; Moghavvemi, \& Omar, 1998).

Moghavvemi et al. in (Moghavvemi, \& Omar, 1998) developed the $\mathrm{L}_{\mathrm{mn}}$ index based on the solution of the power flow equations. The $L_{m n}$ index is a quantitative measure to estimate the distance between actual state of the system and the stability limit. It varies from 0 (no load condition) to 1 (voltage collapse). The $\mathrm{L}_{\mathrm{mn}}$ index is very simple, accurate and fast to be analyzed. In this paper, $\mathrm{L}_{\mathrm{mn}}$ index is considered as the index for voltage security margin.

Fig.1 shows one-line diagram of a transmission line. The $\mathrm{L}_{\mathrm{mn}}$ index of the line between bus $\mathrm{m}$ (sending end) and $\mathrm{n}$ (receiving end) is expressed by the following equation (Moghavvemi, \& Omar, 1998):

$$
L_{m n}=\frac{4 X Q_{r}}{\left[V_{m} \sin \left(\theta-\delta_{m}+\delta_{n}\right)\right]^{2}}
$$

Where $\mathrm{V}_{\mathrm{m}}$ is the voltage magnitudes of $\mathrm{m}^{\text {th }}$ bus, $\delta_{\mathrm{m}}$ and $\delta_{\mathrm{n}}$ are the voltage phase angles of $\mathrm{m}^{\text {th }}$ and $\mathrm{nth}$ bus, $\theta$ is line impedance angle, $\mathrm{X}$ is line reactance and $\mathrm{Q}_{\mathrm{r}}$ is the reactive power at the receiving end. The $\mathrm{L}_{\mathrm{mn}}$ index should be calculated for all transmission lines. The more the index is far from 1 the better voltage security margin is achieved.

Contingencies such as transmission line or generator outages can result in voltage instability in power systems. The system is secure if no contingency can cause the voltage collapse in the system. The maximum $\mathrm{L}_{\mathrm{mn}}$ index of the system after a contingency gives a measure of the contingency severity.

\section{The proposed reactive power market clearing}

In many day-ahead electricity markets, the system operator settles the active and reactive power market in a sequential manner. Therefore, in the time of reactive power scheduling, the hourly active power generations are known.

\subsection{Economic issues}

In this section, a new reactive power market clearing algorithm is proposed which can be used in sequential electricity markets. The algorithm seeks to find the best market schedule in order to minimize the cost of reactive power provision. On the other hand, due to impact of reactive power schedule on power flowing in the transmission line, the algorithm considers transmission loss in the stage of reactive power market clearing. In addition, using this algorithm helps the market operator to take into account the transmission charge payment during market settlement in order to avoid increasing in total market payment.

Consequently, in this paper a new three-component Total Market Payment (TMP) is formulated as the objective function of an OPF formulation. The OPF formulation is as follow:

Min. $T M P=\sum_{i \in \text { gen }} \operatorname{Cost}\left(Q_{i}\right)+\lambda P_{\text {loss }}+R P T C$
Subject to:

$P_{G i}-P_{D i}=\sum^{n} V_{i} V_{j} Y_{i j_{n}} \cos \left(\theta_{i j}+\delta_{j}-\delta_{i}\right) \forall i$

$Q_{G i}+Q_{C i}-\bar{Q}_{D i}^{1}=-\sum_{j=1} V_{i} V_{j} Y_{i j} \sin \left(\theta_{i j}+\delta_{j}-\delta_{i}\right) \forall i$

$Q_{G \min , i} \leq Q_{G i} \leq Q_{G \max , i}^{j=1} \forall i \in S M$

$Q_{C \min , i} \leq Q_{C i} \leq Q_{C \max , i} \forall i \in S C$

$V_{i}^{\min } \leq V_{i} \leq V_{i}^{\max } \forall i$

$\left|S_{i j}(V, \delta)\right| \leq S_{i j}^{\max } \forall i j$

Where:

$\mathrm{n}$ : Number of buses

$\lambda$ : Market energy price

SM: $\quad$ Set of synchronous machines

SC: Set of capacitors

$\mathrm{P}_{\mathrm{Gi}}$ : Active power generated at $\mathrm{i}^{\text {th }}$ bus

$\mathrm{Q}_{\mathrm{Gi}}$ : $\quad$ Reactive power generated at $\mathrm{i}^{\text {th }}$ bus

$\mathrm{P}_{\mathrm{Di}}$ : Active power demand at $\mathrm{i}^{\text {th }}$ bus

$Q_{D i}$ : Reactive power demand at $i^{\text {th }}$ bus 
$\mathrm{Q}_{\mathrm{Ci}}: \quad$ Capacitors generated reactive power at $\mathrm{i}^{\text {th }}$ bus

$\mathrm{V}_{\mathrm{i}}$ : Voltage magnitude of bus $\mathrm{i}$

$\delta_{\mathrm{i}}$ : Voltage angle of bus $\mathrm{i}$

$\mathrm{Y}_{\mathrm{ij}} \angle \theta_{\mathrm{ij}:}$ The $\mathrm{ij}^{\text {th }}$ element of admittance matrix

$\mathrm{S}_{\mathrm{ij}}$ : MVA of line between bus $\mathrm{i}$ and $\mathrm{j}$

In the above OPF formulation, (8) and (9) are the nodal active and reactive power flow equations. The constraints of provision of reactive power by generators, condensers and existing capacitors are considered by (10) and (11), respectively. Limits of all bus voltages and transmission line power flows are imposed by (12) and (13).

\subsection{Technical issues}

As previously discussed, beside economic aspect of market clearing, the system operator should consider the significant impact of reactive power on the system voltage stability.

Therefore, based on the concept of Lmn, it is suggested in this paper to add a new constraint to the OPF formulation. This constraint is as bellow:

$$
L_{m n, i j} \leq v \quad \forall i j
$$

Where $L_{m n, i j}$ is the line stability index of line between bus $i$ and $j$.

This constrained guarantees that the final system operating point of reactive power market clearing has adequate voltage security margin. The parameter $v$ should be sufficiently less than the unity but lessening it more than necessity will increase the operating cost.

\section{Case study}

To show the suitability and effectiveness of the proposed reactive power market clearing algorithm, it is applied on IEEE 24-bus test system (Reliability Test System Task Force of the Application of Probability Methods Subcommittee, 1999). The system consists of ten generators, one synchronous condenser and seventeen load points. Tables 1 and 2 show the market participants' parameters and their active power cost curve, respectively.

Four different cases are studied and discussed. In the first case, the object of the optimization is minimization of reactive power provision cost. Minimization of transmission loss cost and transmission charge payment are the objects of cases 2 and 3, respectively. Finally, in the last case, the proposed TMP is used as the objective function of reactive power market clearing.

In all cases the system loading condition is according to Table 3 . Moreover, the active power market schedule is shown in this table. Table 4 shows the reactive power transmission charge for all lines of the system. All cases are simulated and the results are shown in Table 5. It is noticeable that the parameter $\lambda$, the market clearing price, is equal to $100 \$ / \mathrm{MW}$.

Table 5 includes reactive power schedule for all generators in all cases(C-1 to C-4), transmission loss, RPTC, TMP and also the worth line stability index which shows the system voltage security margin. It is notable that the worth Lmn is the largest line stability index between all transmission lines. The distance of this index from unity indicates the system voltage security margin.

As it can be depicted from Table 5, in case 1, the schedule has the minimum reactive power market payment in comparison with four other cases. In cases 2 and 3, the minimum transmission loss and transmission charge payment are achieved, respectively.

But, it is clear from the table that none of these three cases have the minimum total market payment. The minimum total market payment is achieved when the market is cleared with the proposed algorithm (case 4). It is notable that in all cases, the system operating point lies in the voltage security area and the power system has adequate voltage security margin.

Therefore, the best reactive power market clearing algorithm among all cases is the proposed algorithm which has the minimum TMP while has adequate voltage security margin.

\section{Conclusion}

In deregulated electricity markets, ancillary services are among the most important issues which should be supplied by market participants. Reactive power provision is among the most important ancillary services which has essential role in secure and reliable operation of power system. Due to significant impact of reactive power on economic and technical issues in the system, these two issues should be regarded during market clearing.

In this paper a novel algorithm is proposed for reactive power market clearing in deregulated environments. As the economic aspect, the objective function of the algorithm is designed to minimize total market payment which is summation of reactive power provision cost, transmission loss cost and also transmission charge payment. In 
addition, as the technical issue, the proposed algorithm considers system voltage security margin during reactive power market settlement. Therefore, the operating point of the final market schedule has minimum market payment while it has adequate voltage stability margin. The numerical results show the proficiency of the proposed algorithm.

\section{References}

Bhattacharya, K., \& Zhong, J. (2001). Reactive power as an ancillary service. IEEE Transaction on Power System, 16, 294-300.

California Independent System Operator Corporation. (2000). Ancillary services requirement protocol, FERC electricity tariff.

Dai, Y., Liu, X.D., Ni, Y.X., Wen, F.S., Han, Z.H., Shen, C.M., \& Wu, F.F. (2003). A cost allocation method for reactive power service based on power flow tracing. Elect. Power Syst. Res., 64, 59-65.

FERC Staff Report. (2005). Principles for efficient and reliable reactive power supply and consumption.

Hao, S. (2003). A reactive power management proposal for transmission operators. IEEE Transaction on Power System, 18, 1374-1381.

Hasanpour, S., Ghazi, R., Javidi, M.H. (2009). A new approach for cost allocation and reactive power pricing in a deregulated environment. Electric Engineering., 91, 27-34.

Kundur P. (1994). Power System Stability and Control. McGraw-Hill: USA.

Kargarian, A., \& Raoofat, M. (2011). Stochastic reactive power market with volatility of wind power considering. Energy, 36, 2565-2571.

Kargarian, A., Raoofat, M., \& Mohammadi, M. (2011). Reactive power provision in electricity markets considering voltage stability and transmission congestion. Electric Power Components and Systems, Accepted (to be published).

Moghavvemi, M, \& Omar, F.M. (1998). Technique for contingency monitoring and voltage collapse prediction. IEE Proc. Gener. Transm. Distrrb., 145, 634-640.

National Electricity Market Management Company. (2001). Guide to ancillary services in the National Electricity Market.

New York Independent System Operator. (2008). Ancillary Services Manual.

North Amer. Elect. Reliability Council, NERC. (2000). Operating Policy-10 on Interconnected Operation Services.

Raoofat, M., \& Kargarian, A. (2009). Fast loss allocation in bilateral open access environment using artificial neural networks. IEEE International Conference on Electric Power and Energy Conversion Systems, 1-5.

Reliability Test System Task Force of the Application of Probability Methods Subcommittee. (1999). The IEEE reliability test system-1996. IEEE Trans. on Power Syst., 14, 1010-1020.

Shahidehpour, M., Yamin, H., \& Li, Z. (2002). Market operations in electric power systems. Wiley: USA.

Zhong, J., \& Bhattacharya, K. (2002). Reactive power management in deregulated power systems-A review. Proc. IEEE Power Engineering Society Winter Meeting, 1287-1292.

Table 1. Market participants' parameters ( $\left.\mathrm{S}_{\text {base }}=100 \mathrm{MVA}\right)$

\begin{tabular}{|l|l|l|l|l|}
\hline Provider & $P_{\min }(\mathrm{pu})$ & $\mathrm{P}_{\max }(\mathrm{pu})$ & $\mathrm{Q}_{\min }(\mathrm{pu})$ & $\mathrm{Q}_{\max }(\mathrm{pu})$ \\
\hline G1 & 0 & 2.00 & -0.50 & 1.20 \\
\hline G2 & 0 & 1.92 & -0.50 & 1.00 \\
\hline G3 & 0 & 3.00 & 0 & 1.20 \\
\hline G4 & 0 & 5.91 & 0 & 2.40 \\
\hline G5 & 0 & 2.15 & -0.50 & 1.20 \\
\hline G6 & 0 & 1.55 & -0.50 & 0.80 \\
\hline G7 & 0 & 4.00 & -0.50 & 2.00 \\
\hline G8 & 0 & 4.00 & -0.50 & 2.00 \\
\hline G9 & 0 & 3.00 & -0.60 & 0.96 \\
\hline G10 & 0 & 6.60 & -1.25 & 3.10 \\
\hline Condenser & 0 & 0 & -0.50 & 2.00 \\
\hline
\end{tabular}


Table 2. Active power cost curve of generators

\begin{tabular}{|l|l|l|l|}
\hline Provider & ap* & $\mathrm{bp}^{*}$ & $\mathrm{cp}^{*}$ \\
\hline G1 & 0.0200 & 2.50 & 160 \\
\hline G2 & 0.0284 & 2.90 & 250 \\
\hline G3 & 0.0310 & 2.98 & 205 \\
\hline G4 & 0.0312 & 3.23 & 310 \\
\hline G5 & 0.0296 & 2.99 & 285 \\
\hline G6 & 0.0309 & 315 & 295 \\
\hline G7 & 0.0299 & 3.21 & 410 \\
\hline G8 & 0.0300 & 3.04 & 344 \\
\hline G9 & 0.0288 & 2.92 & 296 \\
\hline G10 & 0.0300 & 2.89 & 190 \\
\hline
\end{tabular}

Table 3. Power demand and active power generation for all buses

\begin{tabular}{|l|l|l|l|l|l|l|l|}
\hline Bus & Pd $(\mathrm{pu})$ & Qd $(\mathrm{pu})$ & $\mathrm{Pg}(\mathrm{pu})$ & Bus & $\mathrm{Pd}(\mathrm{pu})$ & $\mathrm{Qd}(\mathrm{pu})$ & $\mathrm{Pg}(\mathrm{pu})$ \\
\hline 1 & 1.10 & 0.25 & 1.30 & 13 & 2.75 & 0.62 & 4.14 \\
\hline 2 & 1.08 & 0.30 & 1.40 & 14 & 2.10 & 0.45 & 0 \\
\hline 3 & 2.03 & 0.50 & 0 & 15 & 3.35 & 0.70 & 2.15 \\
\hline 4 & 0.84 & 1.41 & 0 & 16 & 1.15 & 0.34 & 1.55 \\
\hline 5 & 0.81 & 0.30 & 0 & 17 & 0 & 0 & 0 \\
\hline 6 & 1.46 & 0.40 & 0 & 18 & 3.46 & 0.75 & 4.00 \\
\hline 7 & 1.37 & 0.60 & 2.60 & 19 & 1.95 & 0.45 & 0 \\
\hline 8 & 1.85 & 0.40 & 0 & 20 & 1.48 & 0.37 & 0 \\
\hline 9 & 1.87 & 0.46 & 0 & 21 & 0 & 0 & 4.00 \\
\hline 10 & 2.09 & 0.44 & 0 & 22 & 0 & 0 & 3.00 \\
\hline 11 & 0 & 0 & 0 & 23 & 0 & 0 & 6.60 \\
\hline 12 & 0 & 0 & 0 & 24 & 0 & 0 & 0 \\
\hline
\end{tabular}

Table 4. Reactive power transmission charge payment (\$ per MVAr per Mile)

\begin{tabular}{|l|l|l|l|l|l|}
\hline From bus & To bus & RPTC & From bus & To bus & RPTC \\
\hline 1 & 2 & 0.015 & 12 & 23 & 0.019 \\
\hline 1 & 3 & 0.018 & 13 & 23 & 0.020 \\
\hline 1 & 5 & 0.015 & 14 & 16 & 0.022 \\
\hline 2 & 4 & 0.017 & 15 & 16 & 0.023 \\
\hline 2 & 6 & 0.020 & 15 & 21 & 0.025 \\
\hline 3 & 9 & 0.017 & 15 & 24 & 0.023 \\
\hline 4 & 9 & 0.016 & 16 & 17 & 0.023 \\
\hline 5 & 10 & 0.017 & 16 & 19 & 0.020 \\
\hline 6 & 10 & 0.019 & 17 & 18 & 0.020 \\
\hline 7 & 8 & 0.020 & 17 & 22 & 0.024 \\
\hline 8 & 9 & 0.017 & 18 & 21 & 0.022 \\
\hline 8 & 10 & 0.018 & 19 & 20 & 0.020 \\
\hline 11 & 12 & 0.020 & 20 & 23 & 0.021 \\
\hline 11 & 14 & 0.018 & 21 & 22 & 0.023 \\
\hline 12 & 13 & 0.022 & \multicolumn{5}{|l}{} \\
\cline { 1 - 3 } & \multicolumn{7}{|l|}{} & & & &
\end{tabular}


Table 5. Reactive power market schedule

\begin{tabular}{|c|c|c|c|c|}
\hline Providers & $\mathrm{C}-1$ & $\mathrm{C}-2$ & C-3 & C-4 \\
\hline G1 & 1.200 & 0.792 & 0.936 & 0.925 \\
\hline G2 & 0.997 & 0.926 & 0.933 & 0.832 \\
\hline G3 & 1.034 & 1.119 & 1.178 & 1.119 \\
\hline G4 & 0.903 & 1.421 & 1.544 & 1.124 \\
\hline G5 & 0.814 & 0.962 & 1.200 & 1.156 \\
\hline G6 & 0.110 & 0.800 & 0.799 & 0.134 \\
\hline G7 & 0.593 & 0.643 & 0.906 & 0.705 \\
\hline G8 & 0.555 & 0.493 & 0.116 & 0.529 \\
\hline G9 & 0.122 & -0.40 & -0.29 & -0.34 \\
\hline G10 & 0.839 & 0.578 & 0.883 & 0.834 \\
\hline Condenser & 2.000 & 1.351 & 0.626 & 1.723 \\
\hline $\mathrm{P}_{\text {loss }}(\mathrm{pu})$ & 0.536 & 0.503 & 0.513 & 0.507 \\
\hline $\operatorname{CostQ}(\$)$ & 986 & 1590 & 1734 & 1082 \\
\hline RPTC(\$) & 709 & 589 & 520 & 612 \\
\hline TMP(\$) & 7055 & 7208 & 7384 & 6764 \\
\hline \multirow[t]{2}{*}{ The worst $\mathrm{L}_{\mathrm{mn}}$} & 0.471 & 0.431 & 0.444 & 0.434 \\
\hline & \multicolumn{2}{|c|}{$\longrightarrow$} & & \\
\hline$L \mathrm{~m}$ & \multicolumn{2}{|c|}{$\mathrm{R}+\mathrm{j} X$} & & \\
\hline
\end{tabular}

Figure 1. Typical One-line Diagram of a Transmission Line 